\title{
ERotisMo FEMENINO EN LA ANTOLOGÍA ARDORES Y FURORES. RELATOS ERÓTICOS DE ESCRITORAS COLOMBIANAS
}

\author{
Female ERoticism In ARDORES Y FURORES. \\ RELATOS ERÓTICOS DE ESCRITORAS COLOMBIANAS
}

María Isabel Reverón Peña ${ }^{1}$, Mario Antonio Parra Pérez ${ }^{2}$

Artículo derivado de la investigación "Artes
visuales y narrativa erótica en Colombia.
Fase II: 2000-2015" financiada por la
Universidad Autónoma de Colombia.

Cómo citar este artículo: Reverón Peña, M. I. y Parra Pérez, M. A. (2019). Erotismo femenino en la antología Ardores y furores. Relatos eróticos de escritoras colombianas. Estudios de Literatura Colombiana 44, pp. 133-149. DOI: https://doi.org/10.17533/ udea.elc.n44a08

${ }^{1}$ maria.reveron@fuac.edu.co

Universidad Autónoma de Colombia

2 mariopa24@gmail.com

Universidad Autónoma de Colombia

Recibido: 15.02 .2018

Aprobado: 03.11.2018

Copyright: $\odot 2019$ EstudiosdeLiteratura Colombiana. Este es un artículo de acceso abierto distribuido bajo los términos de la Licencia Creative Commons AtribuciónNo comercial-Compartir igual 4.0 Internacional

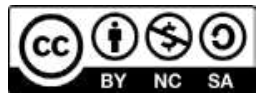

Resumen: el texto muestra cómo la primera antología de relatos eróticos escritos por mujeres publicada en Colombia, Ardores y furores (2003), abre un espacio al deseo femenino dentro de la ficción erótica colombiana del siglo XXI para cuestionar algunas características impuestas a "lo erótico", tales como la restricción a la cópula sexual, la fugacidad y la presencia de cuerpos voluptuosos. Asimismo, el artículo reflexiona sobre diversas formas de presentación del erotismo femenino en la obra y cómo el deseo femenino no puede expresarse ni completa ni conscientemente aún en la sociedad colombiana y por ello se apela en la antología a subterfugios como el desdoblamiento o el sueño.

Palabras clave: literatura colombiana; narrativa erótica; erotismo femenino.

\begin{abstract}
The text shows how the first anthology of erotic stories written by women published in Colombia, Ardores y furores (2003), opens a space to feminine desire within the Colombian erotic fiction of the 21 st century questioning some characteristics that have been imposed on "the erotic thing" such as the restriction to sexual intercourse, the transience and the presence of voluptuous bodies. Likewise, the article thinks about diverse forms of presentation of female eroticism in the work and how the feminine desire cannot be fully or consciously expressed even in Colombian society and because of it one appeals in the anthology to subterfuges such as split personality or the dream.
\end{abstract}

Keywords: Colombian literature; erotic narrative; female eroticism. 
Menciona la reconocida escritora argentina Alicia Steimberg (1993) que El acto de escribir literatura "erótica", es decir una literatura que apela a la sensualidad [...] es un acto masturbatorio para el que la escribe y para el que la lee, y probablemente es por eso, y no por lo que describe, que le da un poco de vergüenza al autor y al lector (párr. 2).

Seguramente, "mucha" de esa vergüenza se la hemos achacado a nuestra herencia occidental judeocristiana, sin tener en cuenta las aclaraciones de Alexandrian (1991) sobre las piezas libertinas de Ausonio - reconocido personaje del imperio cristiano del siglo IV - en cuanto a que "no fueron los padres de la Iglesia sino los filósofos estoicos, como Séneca, quienes comenzaron a llamar 'partes vergonzosas' o 'pudendas' a los órganos genitales” (pp. 28-29). Además, a los caminos de Onán, señalados por Steimberg, habría que unir los territorios de Eros: la materia misma "que se describe" también produce resquemor. Así lo delatan las críticas que se hacen a este tipo de literatura, entre estas, la del crítico George Steiner (1973):

En los escritos eróticos, como en la polución nocturna, la imaginación gira incesantemente en torno al círculo reducido de lo que el cuerpo puede experimentar. El movimiento de la mente en la masturbación no es una danza: es un molino de viento (p. 20).

En el caso de Colombia, también se presenta dicha reticencia por "lo que se describe": no podemos olvidar lo relativamente reciente que es la aparición del cuerpo en la narrativa colombiana y eso, paradójicamente, gracias al periodo histórico que se ha conocido como La Violencia. Como lo afirma Eduardo Jaramillo Zuluaga (1994), "Sólo en el momento en que se documenta la Violencia en las páginas de la novela, el cuerpo aparece de un modo más explícito" (p. 17). ${ }^{1} \mathrm{Y}$ el recelo es mayor si en aquello escrito la sexualidad es el derrotero y no un elemento más dentro del texto, es decir, si estamos frente a una obra de literatura erótica y no de erotismo en la literatura, según la diferencia que ha planteado Alexandrian (1991) en su ya clásica Historia de la literatura erótica:

Debe distinguirse la novela que contiene pasajes eróticos, de la novela erótica propiamente dicha, que tiene por tema el acto sexual con todas sus variantes. La primera evoca libremente la sexualidad porque su autor piensa que los personajes privados de dicho resorte fundamental estarían incompletos; pero de todos modos sirve a un plan más vasto. La segunda sólo expresa la sexualidad, y nada más; y ello con el objetivo de excitar al lector (p. 9).

1 Jaramillo Zuluaga (1994) menciona algunas excepciones a su afirmación como las novelas de Jose María Vargas Vila o fragmentos de De sobremesa de José Asunción Silva, pero aclara que estas obras "fueron marginadas del canon literario con el argumento de que sólo podían complacer a lectores de mal gusto o a historiadores de literatura" (p.24). 
Si queremos completar la lista de reparos, sumemos a una obra de literatura erótica colombiana la autoría de mujeres; pues, como señala Helena Araújo (1989),

Para la latinoamericana, asumirse en función de la corporeidad va a ser siempre una transgresión: la liberación de los instintos vitales ha de pasar por la afirmación del mal, única posible manifestación del deseo. Un deseo que no debía existir en un cuerpo que no debía existir sino como emblema de pureza o fecundidad (p. 46).

Nos queda, así, la obra a la que aquí nos aproximamos: Ardores y furores, la primera antología de relatos eróticos escritos por mujeres colombianas, publicada por la editorial Planeta en el 2003, un año después, y como contraparte, de la antología ¡Aaaaaahhh! Doce relatos eróticos, dedicada a textos de escritores nacionales hombres. Sobre la publicación del texto, Leonel Giraldo, el entonces editor de Planeta, menciona:

Cuando planteamos la idea de hacer un libro de relatos eróticos no pensamos que iba a ser solo masculino, pero quedó así. Por eso, este año [2003] pensamos que sería bueno hacer uno de solo mujeres [...] La mayoría de textos que aparecen en esta publicación ya estaban escritos, en el caso de los hombres fue distinto, con excepción de Efraim Medina, todos los demás lo escribieron para el libro (citado en Gómez, 2003, párr. 3-4).

De hecho, para la búsqueda y localización de las autoras, la editorial Planeta se apoyó en los profesores Luz Mery Giraldo e Isaías Peña. Ardores y furores consta de diez narraciones: "10, Chemin du Devin" de Helena Araújo, "El pañuelo de gasa" de Emma Lucía Ardila, "Rompecabezas" de Andrea Echeverri, "Cuerpos jugados" de Alejandra Jaramillo, "Ella sabe" de Adriana Jaramillo Seligman, "El elegido" de Freda Mosquera, "Ocultó sus ojos tras los párpados" de Diana Ospina, "A solas con el científico" de Gloria Inés Peláez, "Sinfonía erótica" de Lina María Pérez y, por último, "El brazo de reina" de Alexandra Samper.

Aproximarnos a la comprensión de lo erótico en esta obra $\mathrm{y}$, precisando más, de lo erótico femenino resulta relevante en la medida que, como menciona Iván Bloch (1996), citado por Morales (1998), "la concepción de lo erótico en la literatura es de la mayor importancia para comprender el carácter de un pueblo y establecer una opinión de un determinado período de su desarrollo cultural" (p. 29). Así pues, esta obra nos permite reflexionar sobre cuáles formas de relación con el cuerpo sexuado se están reproduciendo, y cuáles subvirtiendo en nuestra Colombia de comienzos del siglo XXI.

Para iniciar, mencionemos cómo la antología busca ampliar la comprensión de lo que es una obra erótica en un siglo que se caracteriza por 
su "hipersexualización". En la antología son escasos los relatos donde el eje es la cópula sexual y nulos aquellos donde los órganos sexuales, el número y duración de orgasmos, así como la producción de fluidos son exagerados; convenciones propias del género y que han sido algunas de las razones utilizadas por la crítica para disminuir el valor literario de este tipo de obras al endilgarles el calificativo de "mera" pornografía. ${ }^{2}$

En esta línea de ideas, Ardores y furores enriquece la lectura de lo considerado erótico al incluir en este campo la caricia de una pañoleta, los cuerpos (que bien puede quedarse en los preliminares del acto sexual), el placer de la mirada, el goce bucal (propiciado por el sabor del helado, del brandy, de la sangre menstrual). Otro aspecto en el que puede verse dicha apertura de lo erótico es en el desplazamiento de la importancia del deseo al amor: lo frecuente en el género es que el deseo, y no el amor, sea el eje por el que transitan los personajes, pues el deseo apunta a lo volátil y fugaz, mientras que el amor a lo imperecedero, a lo continuo. En la antología, el encuentro de los cuerpos está asociado a la felicidad y, por momentos, a la construcción de relaciones duraderas. Así, por ejemplo, en la tercera parte del cuento "Rompecabezas", de Andrea Echeverri, el narrador se dirige a un Ser Creador (cuya identidad queda sin determinar) para enunciar que la pareja protagonista del relato, aún sin conocerse —o justamente por ello-, al unir sus cuerpos en el limbo logra la "felicidad absoluta"; aunque esta felicidad no será eterna, pues la pareja será separada:

Los juntas aquí, en este limbo oscuro, para que descubran que son las piezas del rompecabezas perfecto, que pueden alcanzar el éxtasis unidos, y luego los sueltas en su mundo, solos, lejanos, anhelantes de encontrarse pero sin saber cómo: ni siquiera se han visto, nada saben el uno del otro, ni siquiera si son reales... Y sin embargo, guardarán la esperanza eternamente (Echeverri, 2003, pp. 46-47).

Del mismo modo, en el relato "El elegido", Freda Mosquera alude al ser mítico presentado por Platón a través del discurso de Aristófanes en El Banquete: "Él entró en ella muchas veces y se quedaron largo tiempo entrelazados, adheridos, como si fueran las dos partes perdidas de un

Otras razones que esgrimen aquellos que apoyan la exclusión de la pornografía del dominio de la literatura son las señaladas y desmontadas por Susan Sontag (1967) en su texto "La imaginación pornográfica": a) la intención de la pornografía (despertar la excitación sexual) riñe con la del verdadero arte. b) Las obras pornográficas carecen de la verdadera forma de la literatura: comienzo-nudo-desenlace. c) El papel que desempeña el lenguaje en las obras pornográficas es tan solo instrumental; por tanto, se descuida el uso de este como forma de expresión. d) La pornografía no tiene en cuenta la complejidad de los retratos psicológicos y sociales, sino que describe únicamente "las transacciones infundadas e incansables de órganos despersonalizados" (p. 49). 
ser mítico que no se hallaba a sí mismo desde tiempos inmemoriales" (Mosquera, 2003, p. 69). La completud que surge en el encuentro deseante de los cuerpos alcanzada por una mujer que paga por los servicios de un prostituto anticipa el final del relato: se intuye el abandono de una relación meramente comercial para comenzar otra forma de relación fuera del burdel donde el hombre trabaja. Una relación en la que parece inevitable el deseo de posesión: “-¿Cuánto me costaría comprarte para siempre?- le preguntó [Alejandra al hombre]. Y entonces se imaginó descendiendo de un avión, y luego entrando en el aeropuerto de su ciudad, arrastrando una enorme jaula, con él adentro, como un trofeo ganado en el extranjero" (p. 69).

El desplazamiento del deseo al amor y la completud que este conlleva también se menciona en "Ocultó sus ojos tras los párpados", de la autora antioqueña Diana Ospina, esta vez no solo asociada a la relación de pareja, sino a la regresión a la relación madre-hijo durante el periodo de lactancia: "Su rostro, su cuello, su pecho aparecen entre mi boca como fragmentos de vida que recobro con cada succión, vez a vez más urgente y necesaria, como un bebé de días con el pecho de su madre" (Ospina, 2003, p. 81). Parecería así que, en medio de la despersonalización que caracteriza el deseo (no importa quién toque, sino cómo toque), surge, en estos relatos de mujeres, el amor como la posibilidad de dar un rostro a esa masa amorfa del baile libidinal sin perder por ello el goce de los cuerpos.

Además de no restringir lo erótico a la cópula sexual ni a la fugacidad del deseo, consideramos que, en la mayoría de relatos, la irrelevancia del físico de los personajes en comparación con otras características es un tercer aporte de la antología a la narrativa erótica en Colombia. Más importante que describir cómo son los cuerpos que gozan, lo importante es justamente esto último: que gozan. Una de esas "excepciones" es "El elegido". Allí tanto la mujer como el hombre tienen cuerpos cuidados, trabajados. El cuerpo del hombre aparece en este cuento como un elemento que se suma a la cadena de estímulos para satisfacer las fantasías heterosexuales de una mujer en un exquisito burdel, espacio de goce por antonomasia.

En relación con el cuerpo femenino, los relatos muestran cuerpos alejados de la esbeltez culturalmente asociada al deseo: hay cuerpos enfermos como Rosella y Ruegg en el relato de la escritora Helena Araújo "10, Chemin du Devin"; u obesos, como el de Mari en el cuento de Alexandra Samper, "El brazo de reina", aunque hay que hacer la salvedad que en el encuentro erótico 
que en este relato se da, Mari no es valorada por sí misma, sino porque sus manos le recuerdan al joven que le llevó un domicilio a su casa, el sabor de la masa cruda que hacía su tía en Urumita (Guajira). También aparecen cuerpos femeninos faltos de hermosura como el de Leonora en "Sinfonía erótica" de la bogotana Lina María Pérez (2003), carencia que "suple" con un cuerpo "desparpajado a la hora del sexo: caderas desinhibidas, senos apetecibles, bríos voluptuosos" (p. 93). Incluso, hasta se deja sin nombrar el sexo femenino, como ocurre en "Rompecabezas": "siento que empiezo a inundarme... Cómo es de agradable sentir su beso ahí, y presumir que no me exigirá (tácitamente, sobra decir) que le pague con la misma moneda..." (Echeverri, 2003, p. 45). Pero en esta última referencia podríamos preguntarnos si con el recurso se amplía el goce femenino al no concentrarlo en la vulva, en el goce fálico tal y como lo entiende Lacan (1989) en su Seminario Aún, o si se le quita existencia pues, como sabemos, lo que no se nombra no existe.

En la descripción de los hombres, más allá del físico resulta importante su experticia en las artes amatorias: no hay aquí hombres apresurados ni en caricias ni en secreciones. Son hombres que permiten que se cumpla a cabalidad la locución latina Post coitum omne animal triste est sive gallus et mulier (Después del coito todo animal está triste excepto el gallo y la mujer). Así, en "Rompecabezas", la mujer refiere el virtuosismo (real o imaginario) del desconocido, a diferencia de Mario, su pareja actual:

Se nota que tiene experiencia en el asunto, o mejor, como fruto de mi imaginación, sabe perfectamente qué debe hacer, cómo y a qué ritmo [...] todo un sueño que un amante se ocupara de darme toda la dicha sin exigirme nada en absoluto, ni siquiera demostrar el clímax. ¡Los hombres piden tanto! "Haz esto, date la vuelta, ¿llegaste?, dime todo lo que sientes" (Echeverri, 2003, pp. 44-45).

Ese amante perfecto en "El elegido" es ubicado en relación con la animalidad:

[...] un joven delgado, completamente desnudo, de músculos firmes, con un pelo negro de seda que le caía sobre los hombros y los ojos verdes de gato salvaje [...] se levantó y se acercó a la ventana, sonriéndole, con el sexo erecto, frotándolo, como un animal solitario [...] El sexo del hombre le latió en el vientre como una serpiente viva (2003, pp. 67-68).

Esta asociación de la sexualidad con lo animal en oposición a la de erotismo con lo humano ha sido suficientemente señalada por varios pensadores. En este sentido, Georges Bataille (1988) refiere que, si bien la actividad sexual es común a animales y a seres humanos, 
[...] aparentemente solo los hombres han hecho de su actividad sexual una actividad erótica, y lo que diferencia al erotismo y a la actividad sexual simple es una investigación o búsqueda psicológica independiente del fin natural dado en la reproducción y en el ansia por tener niños (p. 23). ${ }^{3}$

Del mismo modo, Octavio Paz (1995) afirma que "el erotismo no es mera sexualidad animal: es ceremonia, representación. El erotismo es sexualidad transfigurada: metáfora" (pp. 10-11). Así las cosas, creemos que el "retorno a la animalidad", a la "mera sexualidad", a los "bajos instintos" se puede leer en la antología como una estrategia de amplificación del goce, dado que, al no tener lenguaje articulado, los animales no tienen la limitación que tenemos los humanos para la expresión del goce; pues si bien el lenguaje es necesario para ello, también lo limita. Ya el psicoanalista francés Gérard Pommier, citado en González, Moreno y Sanmiguel (1997), han referido cómo las consonantes frenan el goce "vocálico" y, con ello, se entiende que sea el grito/la vocal el sonido que aparezca en los momentos de máximo goce humano: "la posición de las vocales y la de las consonantes es totalmente distinta respecto al goce de hacer sonido al hablar. Las vocales tienen algo de abierto, las consonantes tienen algo de cerrado; y la ley cierra el goce de las vocales: 'aaa', 'ooo'” (p. 165).

El goce amplificado en el lenguaje se percata con facilidad en " 10 , Chémin du Devin", esta vez con el sonido vocálico de la conjunción "y" (i griega), la supresión de puntos y las repeticiones de palabras:

Atontada, Rosella no tuvo ya alientos de seguir en esa lucha inútil mientras Ruegg le sacaba la blusa. Al contrario, de pronto parecía consentir, sí, asentir, inclusive colaboraba con gestos abruptos y como descontrolados [...] ella misma estaba acezando, jadeando, ella misma, sí, ella misma llevando a tanteos hasta sus labios la mano febril de Ruegg, los dedos temblorosos de Ruegg, ella misma lamiendo golosa, desesperadamente, ella misma y su lengua raspándose en ese pellejo áspero, salado, sus labios chupando como si de ese modo pudiera saciar la sed que ahora Ruegg sí estaba saciando, porque ya sentía el peso de su cabeza y el roce húmedo de su boca y su lengua, y sentía a Ruegg abriéndole los muslos y clavándose allí, buscando,

3 También hay detractores de la afirmación referida a la carencia de imaginación cuando se habla de sexualidad animal. Uno de ellos es el director de cine español y de la colección de literatura erótica La Sonrisa Vertical (1977-2002), Luis García-Berlanga, quien menciona: "Yo no estoy seguro de que, del mismo modo que pueden sentir terror, algunos animales no tengan necesidad de adornar sus actos amorosos, de embellecerlos, de introducir en ellos alguna variación repentina. Ciertos pájaros se exhiben y se hacen regalos, los gatos se muerden en el cuello, los ciervos y los leones luchan por las hembras. Se me dirá que lo llevan en sus genes y que no pueden hacer otra cosa. Pero también hay animales que practican el sexo sin fines de procreación. Se masturban con objetos, por ejemplo, o desarrollan preferencias hacia otras especies, entre ellas la humana, y se desentienden de las suyas. No sé en qué zoo, quizá en el de Madrid, había un pavo real que se había enamorado de un puercoespín, y le hacía la corte” (1995, pp. 7-8). 
buscando, lamiendo más y más hondo hasta entrar poco a poco mientras Rosella se retorcía y se cimbraba y gemía y temblaba y le tiroteaba el cabello suplicándole que no más, por favor, que no más y le tiroteaba hasta hacerle levantar la cabeza y Ruegg tenía los mismos ojos vidriosos, la misma mirada extraviada, pero los labios, los dientes, las encías como si sangraran y era su sangre, la de Rosella y Rosella gemía una vez más con una mueca frenética (Araújo, 2003, pp. 33-34).

Este relato en particular introduce elementos diferenciadores en relación con otros de la narrativa erótica colombiana: por un lado, la sexualidad entre personas mayores y enfermas (Ruegg tiene hepatitis y Rosella, cistitis) y con ello el alejamiento de la asociación sexualidadpenetración-fuerza-vigorosidad-juventud-belleza, tan generalizada en este tipo de literatura; por otro, la reivindicación de la sangre menstrual en el goce del encuentro de los cuerpos: en el cuento el deseo del hombre lleva a otro plano el "agobio" que la mujer siente por su menstruación y el rechazo cultural a la que esta se somete.

Sobre este último punto quisiéramos insistir, puesto que las referencias a la nieve roja (otra forma de denominar a la menstruación) son de por sí escasas en los textos literarios, y aún más en los relatos eróticos. Además, cuando las alusiones aparecen, se dan desde la vergüenza y el asco, y no desde la exuberancia del goce. Al decir esto, pensamos en "Zaynab", un relato de Enrique Serrano que aparece en la antología de cuentos eróticos Aaaaaahhh...! Doce relatos eróticos (2002).

Ahora bien, retornando a Ardores y Furores, tenemos que tanto en "10, Chemin du Devin" como en la antología en general, el principal motor que enciende el deseo erótico es la infidelidad. Pero, en este punto, la obra no se distancia de lo característico del género: como menciona Patrick Hanan (1992), "Está en la naturaleza de la ficción erótica la exploración del territorio prohibido" (p. 13). Habría que preguntarse, entonces, qué ha sido para la mujer colombiana lo prohibido - sexualmente hablando - para que pueda surgir con ahínco en la narrativa erótica. ${ }^{4} \mathrm{Si}$ se miran las prohibiciones impuestas por la Iglesia, el Estado y la sociedad patriarcal, es evidente que la infidelidad es una de las principales dentro de la ética entre esposos, y contra esta imposición la mujer se rebela en este tipo de literatura: encontramos que en " 10 , Chemin du Devin", Rosella tiene dos encuentros "imposibles" con un hombre impensable, Ruegg, quien es la antitesis de la pulcritud — chaqueta deshilachada, nicotina,

En la vía de las prohibiciones culturales, Hanan (1992) nos recuerda cómo en la ficción erótica china el "territorio prohibido" era el adulterio, mientras en la europea era la desfloración. 
caspa en las hombreras, "costras blancuzcas cubriendo las entradas de aquella melena hirsuta" (Araújo, 2003, p. 33) - ; en "Rompecabezas", una mujer en el limbo "se deja hacer" de un hombre que no es su pareja, y lo sabe; en "Ocultó sus ojos tras los párpados", Ángela tiene sexo con Miguel mientras recuerda sus encuentros con Juan; en "Sinfonía erótica", la infidelidad resulta ser una venganza de Leonora hacia su machista esposo, en el sentido de "darle un poco de su propia medicina...", y finalmente, en "El brazo de reina", Mari deja que el joven que lleva domicilios saborée sus robustas manos, pensando en que el mancebo pueda cargar en su ancha espalda los problemas que ella tiene con su marido.

Es más, la infidelidad llega a tal punto que no solo se goza al practicarla, sino que el goce también aparece cuando es la propia pareja quien la practica. Así se muestra en "Ella sabe", de la escritora y periodista Adriana Jaramillo Seligman (2003), donde la protagonista se identifica con su marido infiel: Lucía quería saber "cómo era la sensación de su marido cuando sacaba la lengua debajo de ella [la amante], qué placer lo ataba a ese cuerpo que salvaba vidas con la bata puesta y causaba tanto dolor cuando se desnudaba" (p. 58). En este cuento, el título mismo plantea el juego entre los significantes saber y sabor: Lucía sabe (de la infidelidad de su esposo) y goza del sabor del helado que lame; y esto se conjuga en el querer saber el sabor de la amante de su esposo. El goce de la mirada se une, pues, al orgasmo producido ante la estimulación del clítoris de la garganta: ${ }^{5}$

Se clavó entre los labios otra cucharada rápida y en seguida volvió a llenar el cubierto, pero esta vez quedó lamiendo pausadamente la nata helada llena de grumos oscuros, estiró mucho la lengua para que el sabor se extendiera por todas partes, las encías, el paladar, las partes más profundas de sus cavidades bucales, y la llevó de ahí, ya arenosa y tibia, a las amígdalas que esperaban con ansia que llegara directo al clítoris de la garganta, esa campana diminuta que al roce se estremece (p. 57).

Solo que el orgasmo bucal en el relato está asociado a la niñez (y a su dulzura, la dulzura del helado) y el orgasmo vaginal (de la amante), a la muerte, a ese goce que estaría "más allá" del placer circunscrito a las convenciones sociales. En esta línea de ideas, Lucía ocuparía el lugar de esa niña que goza al ver las relaciones sexuales de los adultos, una variante de esa "escena originaria" trabajada por Sigmund Freud. Incluso en el diálogo imaginario de Lucía, su esposo le dice: “ $¿$ Te traigo algo de postre, algo dulce bonita, como

5 Nos resulta imposible no asociar esta forma de orgasmo con la de la protagonista de la clásica película pornográfica dirigida por Gerard Damiano en 1972: Garganta profunda. 
tú?” (p. 59). Mientras Lucía es "lo dulce", la amante provoca en su cirujano esposo el retorno a la animalidad, a la que ya nos hemos referido: "estaba excitado y tembloroso, apretaba los dientes como un animal iracundo, y a veces abría la boca como si aullara en silencio [...] le metía el hocico entre el vientre como husmeando en esa piel de cirujano" (pp. 57-58).

Además de transgredir los acuerdos contraídos (matrimonio), en la antología se muestra la violación de esa ley cultural fundamental que es el incesto. En "Cuerpos jugados", su autora, Alejandra Jaramillo, privilegia el campo de la imaginación y, como el título del relato lo indica, pone en juego los cuerpos de los protagonistas llevándolos a situaciones que sobrepasan las imposiciones culturales; se trata, entonces, de estar en el límite entre la sensualidad y la perversión. El juego consiste en ponerse una máscara frente a los otros (los propios rostros amistosos e inocentes) para dar rienda suelta al deseo incestuoso en un departamento vacío: "empezaban las largas sesiones de desgarre, de placer. Instrumentos filudos, llamas, hielos, manos desconocidas, cuerpos varios asomándose a la claridad de nuestra piel" (Jaramillo, 2003, p. 51). Pero el placer, según se menciona en este relato, no puede ser permanente, pues comienza a hartar: "también del exceso nos agobiamos, nunca sabremos cómo vivir en lo permanente. Vivimos en la búsqueda incesante de la certeza; esperamos nunca encontrarla" (p. 53). Postura semejante se trabaja en "Ella sabe", en donde la decisión asumida por Lucía ante la infidelidad de su esposo es "no decidir" y salir de su casa antes de ser descubierta por la pareja de amantes, sintiendo que "cuando el placer se vuelve constante empieza a heder a putrefacción, a cuerpo deshecho por una dicha que la naturaleza no contiene" (Jaramillo Seligman, 2003, p. 59). Y este es otro rasgo distintivo de la antología frente al género: en un subcampo literario donde se privilegia el placer ilimitado, aquí parece preferirse el goce en esa distinción que ha hecho Lacan (1989) en su relectura de Freud: el placer como freno al goce; el placer como explicable y el goce no en tanto escapa a la voluntad del sujeto.

Otro de los móviles que propician el encuentro erótico en Ardores $y$ furores es lo desconocido: si se trata de un otro desconocido, ocho de los diez relatos incluyen el tema del encuentro erótico entre extraños. Dentro de esta categoría incluimos a aquel que permite la evocación del otro conocido, como ocurre en "El brazo de reina", donde Mari da vía libre a su deseo porque ubica al joven que le lleva un domicilio como la personificación del ángel San Gabriel, de modo que para ella el encuentro erótico se enmarca en un vaivén entre lo celestial y lo infernal: 
¡Qué barbaridad!, es idéntico al ángel de la iglesia [...] No, que yo le haya visto las nalgas al ángel. ¡Ni que Dios lo permita! No. Pero en misa, cuando uno lo analiza se da cuenta de que debajo de esa túnica el ángel tiene que tener necesariamente esos mismos músculos que en este momento Dios me está permitiendo vislumbrar en este joven [...] ¡Es el querubín de los infiernos, el ángel caído! (Samper, 2003, pp. 103, 108).

No obstante, lo desconocido no necesariamente es el otro, pues también puede corresponder a un objeto. Así, en "El pañuelo de gasa", de la profesora Emma Lucía Ardila, se plantea el erotismo desde el descubrimiento de nuevas sensaciones; esta vez, desde el color y la suave textura de una pañoleta. La historia se puede resumir así: un hombre mayor, ya canoso, conoce a Támara, una colegiala que todos los miércoles disfruta de un helado distinto en un mismo lugar. Hay una atracción mutua y uno de esos miércoles el hombre le entrega a Támara una pañoleta que se le ha caído a una "fina" mujer en el centro comercial y que él ha recogido y guardado para ella:

La pañoleta se desenvolvió largamente y extendió el perfume por el aire. Ella abrió los ojos y se encontró con los de él, muy cerca de su cara. El aroma los envolvió a los dos, y también la efusión de colores que despedía la tela. La niña, con una marca de chocolate en la boca, entreabrió los labios, acercó el pañuelo al rostro y de nuevo cerró los ojos. Una sensación desconocida la invadía, era como un gusto que le llenaba todo el cuerpo y que no sabía explicar (Ardila, 2003, p. 37).

Mencionaremos aquí una última forma de presentación del erotismo en la antología y es la relativa al deseo de los personajes femeninos. Al respecto, debe rescatarse el protagonismo que se da a los personajes femeninos y a su deseo. En la mayoría de los relatos sus protagonistas son mujeres - pese a que en apariencia en algunos cuentos sea el hombre quien lo es ("Pañuelo de gasa" y "Sinfonía erótica") — que se asumen como sujetos deseantes y no meros "objetos de deseo" dentro de encuentros heterosexuales, y aquí debe mencionarse que la totalidad de los relatos aborda este tipo de relación (aunque en "Pañuelo de gasa" la relación sea con un objeto: una pañoleta). No obstante, en varias de estas historias encontramos de manera reiterativa que la mujer no asume de manera consciente su deseo, sino que aparecen subterfugios: el personaje se desdobla ("no soy yo la que goza, es otra en mí”), o utiliza la imaginación para tener sexo con un otro distinto al otro real con quien se está. Si bien es claro que en el goce los recursos imaginarios se activan sobremanera, aquí no hablamos de esa otra faceta individual que surge en el encuentro sexual y no se puede reconocer como propia, sino en recursos empleados por las autoras para que las protagonistas de sus relatos no asuman o no puedan asumir de modo consciente su deseo, sino que, de cierto modo, se evadan del goce. 
En este punto valdría recordar el aporte de la reconocida editora de TusQuets, Beatriz de Moura Gurgel (1999), sobre la lectura "realmente indagadora" de la literatura erótica a la que se refirió en un Seminario de la Universidad de Jaén:

La literatura de cualquier género es, por sí misma, en sí misma, fuente de placer y conocimiento. Pero la erótica no sólo es fruición y goce [...] es también y, sobre todo, cuando lo es realmente, trabar conocimiento con el Mr. Hyde que todos llevamos dentro, comprenderlo, aceptarlo, educarlo y convivir con él en la mayor armonía posible, como seres humanos cabales y civilizados (p. 156).

En el sentido de lo mencionado anteriormente, resulta pertinente, entonces, preguntarnos sobre qué aspectos de nuestro Mr Hyde [Mrs Hyde] colombiano son los que aquí se están evidenciando: ¿por qué la mujer no asume de manera frontal su deseo, sino que tiene que "justificar" el acercamiento sexual apelando al recuerdo borroso, al sueño, al fingimiento, a la inexactitud en la descripción de los encuentros, a la transformación de lo humano en angélico? ¿A comienzos de este siglo "hipersexualizado", no estábamos preparados los colombianos - desde la acción y no desde la práctica discursiva - para aceptar que la mujer goza como y cuando quiere?, ¿seguíamos sin darnos cuenta, como menciona Diana Torres (2014), que aquello que creemos nuestro (nuestra sexualidad, nuestro deseo) es territorio colonizado?

Las respuestas a estas últimas inquietudes parecen afirmativas si revisamos en la antología estos recursos "facilitadores" del goce femenino. Así, en "10, Chemin du Devin", los encuentros sexuales entre Rosella y Ruegg ocurren bajo las égidas de la imprecisión y el desdoblamiento. El primer encuentro sexual (sexo oral) entre Rosella, una mujer que vive en Suiza con su esposo André, con quien lleva más de 10 años de casada, y Ruegg, un hombre viudo que sobrepasa los sesenta años, es presentado así:

No, no, para lo que siguió no podía haber explicación. Había sido tan absurdo que ni siquiera podía recordarlo bien, le llegaban apenas fogonazos como de una película velada a trechos [...] era mejor restarle importancia al incidente, porque había sido eso, un incidente, algo sin antes ni después. Algo que había brotado así, estallado así, por fuera de todo control. Porque ella no había podido controlarse: era como si otra hubiera actuado por ella. De ahí ese desdoblamiento, esa compulsión que... (Araújo, 2003, pp. 25, 28).

Otro de los recursos que se muestran para no asumir de modo consciente el deseo femenino es acudir al fingimiento, lo onírico y la imaginación, tal como aparece en "Rompecabezas", en donde tanto el hombre como la mujer viven una situación poco comprensible: nos enteramos al final de que están muertos, "en el eslabón de enlace entre dos vidas" (Echeverri, 2003, p. 46). 
La mujer menciona:

No entiendo nada. Sé que Mario no está, y además no es su estilo. Así que debo estar teniendo un sueño inusual [...] No es nada desagradable, lo admito, pero me inquieta no reconocer a quien me toca. Sin embargo estoy tan cansada, tan aletargada que no logro actuar; ni siquiera abro los ojos, en el fondo porque no quiero despertarme. Mejor me abandono a mi placer por extraño que sea (pp. 43-44).

Y en "Ocultó sus ojos tras los párpados", se apela al recuerdo para no enfrentar la ausencia de deseo de Ángela por Miguel. El relato alterna la construcción de dos historias: por un lado, la historia "presente" de Ángela y Miguel; por otro, una historia "pasada", un recuerdo que viene a la mente de Ángela de cuando ella estaba con Juan, "ese gran amor necesario, ese primero y único amor" (Ospina, 2003, p. 75), con quien llevaba tres meses saliendo. Todo ocurre mientras los personajes, en un automóvil, se van de la ciudad y vuelven a esta; solo que la trama se invierte: mientras en el presente es Miguel quien busca seducir a Ángela y ella escapa todo el tiempo de él, en el recuerdo es Ángela quien quiere hacer el amor con Juan y él se escabulle. Hasta que al final, las dos historias confluyen, tanto Miguel como Ángela logran su cometido: mientras Ángela, ocultando sus ojos bajo sus párpados, recuerda el lúbrico encuentro con Juan, Miguel la posee en el carro. Solo que al volver a la "realidad", Ángela se da cuenta de que está con Miguel y no con Juan, aparece un grito insondable y "un silencio que ahora les pertenece a ambos" (p. 82). El presente, entonces, trae de manera "redoblada" el recuerdo, como se anticipa en el epígrafe de Marcel Proust de Por el camino de Swann que utiliza la escritora en el sentido de que aquello de lo que más huimos, es aquello que más fuertemente se nos presenta; y la felicidad... solo está en el recuerdo, aquí asociada al amor.

En "Sinfonía erótica", el fingimiento - la representación — se da en un nivel mayor, pues Leonora interpreta con un otro una sinfonía erótica para su voyeur marido en El Palacete, lugar al que este semanalmente asiste para deleitarse viendo sexo en vivo. La engañifa se incrementa porque durante todo el relato se nos ha hecho creer que Leonora no sabe ni de las andanzas ni de las infidelidades de su esposo y al final se demuestra su "astucia", 6 pues cuando él quiere conocer a la mujer que le dio tan grandes satisfacciones a su ojo por ser una "hembra voraz en la iniciativa, ávida en la réplica y sabia en dirigir posiciones con las que retarda el orgasmo 6 La astucia femenina es un tema recurrente en la narrativa erótica. Baste mencionar obras como Autobiografía de una pulga (anónimo) y Memorias de una cantante alemana (Wilhelmine Schroeder-Devrient) para darnos una idea. 
de su amante de turno" (Pérez, 2003, p. 95), descubre con espanto que esa mujer es su esposa Leonora, quien sonríe burlonamente. Y la impresión se aumenta por las características endilgadas a Leonora: una mujer bien educada, a la altura profesional y social del protagonista y quien, además, "no esgrime remilgos feministas" (p. 93).

Ahora bien, ese elemento de "extrañeza" que propicia el encuentro sexual no solo atiende a los personajes, sino a ambientes o fenómenos naturales. Así, en "10, Chemin du Devin", el deseo femenino es justificado por el tiempo y espacio donde ocurren las acciones del relato: un verano en Suiza. El calor del cuerpo es una prolongación del calor de la ciudad: es en agosto, cuando "la ciudad se calentaba y hasta se alegraba desordenándose, relajándose" (Araújo, 2003, p. 11), que puede darse el encuentro sexual entre Rosella y Ruegg. Del mismo modo ocurre en "El elegido", donde los acontecimientos transcurren en el verano, pero esta vez norteamericano. Este aspecto resulta importante, pues puede leerse como una crítica hacia la postura conservadora que en Colombia se tiene frente a la exploración del cuerpo, y la afirmación de la necesidad de pasar por el referente extranjero para ampliar la apertura hacia el goce. ${ }^{7}$

En el relato "A solas con el científico", de la escritora y antropóloga manizalita Gloria Inés Peláez, es otro elemento extraño, un cometa, el que propicia el encuentro sexual. Al inicio del texto se plantea que, por influencia de un cometa, Francisco José de Caldas ha amado "sin temores" a la narradora protagonista, quien se desempeña como copista del científico. Ella, con intenciones de terminar de darle a Caldas sus instrucciones en el "arte del amor", decide volver a visitarlo en el Observatorio, de modo tal que en este segundo encuentro termina bajo la frazada junto al cuerpo del científico, quien explora de modo inexperto sus sinuosidades; pero él, una vez "nutre su inteligencia", se aparta, "cierra su cuaderno" (Peláez, 2003, p. 89). Aquí, pese a que es la mujer quien busca, quien fragua el encuentro, no por ello su deseo se satisface: el acto sexual se queda en los preliminares, lo que lleva a la narradora a mencionar al final del relato que "Acaso el cometa que le

En este mismo sentido puede leerse la posición del escritor Hernán Hoyos, considerado por algunos como "el pornógrafo caleño" o "el Sade colombiano"; en varias de sus obras de sexo-ficción (término acuñado por el autor para superar el adjetivo pornográfico con el que era señalado su trabajo): lo extranjero (lugar o personaje) se caracteriza por ampliar la mirada frente al goce. Al respecto, sugerimos revisar nuestro trabajo "No es porno, señoras y señores, es sexo-ficción: una mirada crítica a la 'modernidad' caleña de los años setenta del siglo xx en Colombia en la obra Aventuras de un impotente de Hernán Hoyos". 
perturbó días antes se encuentra muy lejos y ya es tarde para ponerlo de nuevo a mi favor" (p. 89).

\section{A modo de conclusión}

Nos recuerda Morales (1998), apoyándose en Foucault, que desde la Grecia clásica, en la relación erastés-erómenos (amante-amado), ambos roles asumidos por hombres, se ha ubicado la actividad de Eros en erastés. La mujer, primero desde la ausencia en este tipo de relación y, luego puesta en el lugar de erómenos en el amor udrí y en el amor cortés, logra paulatinamente, desde mediados del siglo xx, asumir el rol de poseedora de Eros o, lo que es lo mismo, pasar de ser objeto de amor a amante.

Este paso es evidente en la antología Ardores y furores que aparece en el 2003 y viene a enriquecer el panorama erótico colombiano revelándonos algunas formas de concepción del erotismo femenino. En esta obra, aunque se privilegian lo desconocido y la infidelidad como móviles del deseo sexual reafirmando la idea que no hay nada más antierótico que el matrimonio, al mismo tiempo podemos ver que se cuestiona la transgresión como condición sine qua non de la ficción erótica al contemplar, en algunos relatos, la construcción de un vínculo permanente que pueda integrar la antinomia sexualidad-amor, tan propia del modelo erótico masculino.

Ahora bien, en cuanto a la asunción de la mujer como sujeto deseante, vemos que su interés está puesto en la figura de hombres avezados en las artes amatorias para dar cumplimiento a sus fantasías heterosexuales. Por un lado, los hombres elegidos permiten el retorno a lo instintivo, a la animalidad; presuponemos, a un goce superlativo en tanto el animal se fuga de la prisión de la palabra, de la simbolización.

Este escape, en algunos relatos, y como si se tratara de equiparar las posibilidades de goce entre hombres y mujeres, se da en lugares que han sido por siglos efigie del goce masculino: los burdeles. Así, en "El elegido" aparece una mansión erótica que le permite a la mujer cumplir la fantasía de poder estar con cualquiera que desee, que le permite ser dueña y señora de su cuerpo y de su tiempo. En esta equiparación, incluso la figura del hombre se vuelve prescindible; el hombre resulta no solo disminuido, sino innecesario para el goce femenino cuando se tiene entre manos un consolador. En "Sinfonía erótica", aunque es la mujer quien trabaja como prostituta, no lo hace desde la posición resignada de la necesidad, sino desde la elección del goce carnal. No obstante, estos lugares en los que se puede expresar con 
desenfado el goce femenino exigen tarifas complacientes que solo pueden ser asumidas por personas adineradas. En relación con lo anterior, y con la ubicación de algunos personajes en espacios extranjeros (Suiza, Estados Unidos) y determinadas clases sociales, pareciera que si bien la antología rescata el deseo de la mujer, esta solo podría gozar de forma plena si tiene dinero o está fuera de Colombia.

Por otro lado, buena parte de los encuentros eróticos que se dan en la antología son con hombres desconocidos y en situaciones extrañas (se desdobla la mujer protagonista, se está en el limbo, pasa un cometa...). Tal condición la hemos leído como la expresión de la dificultad de la mujer para asumir su deseo, de manera consciente, en la Colombia del siglo XXI, y desde un marco distinto al de la heterosexualidad. En síntesis, la antología Ardores y furores representa los zigzagueos de la voz erótica femenina en el despertar del siglo xxi en Colombia. Una voz que aún necesita emplear subterfugios para afirmar, sin ambages, que goza. Una voz que aún requiere mayores estudios y más oídos para escucharla.

\section{Referencias bibliográficas}

1. Alexandrian, S. (1991). Historia de la literatura erótica. Bogotá: Planeta.

2. Araújo, H. (1989). La Scherezada Criolla. Ensayos sobre escritura femenina latinoamericana. Bogotá: Universidad Nacional de Colombia.

3. Araújo, H. (2003). 10, Chemin du Devin. En Ardores y furores. Relatos eróticos de escritoras colombianas (pp. 11-34). Bogotá: Planeta.

4. Ardila, E. (2003). El pañuelo de gasa. En Ardores y furores. Relatos eróticos de escritoras colombianas (pp. 35-38). Bogotá: Planeta.

5. Bataille, G. (1988). El erotismo. Barcelona: TusQuets.

6. De Moura Gurgel, B. (2000). La experiencia interior. En M. Ledesma (Ed). Erotismo y literatura (pp. 145-156). Jaen: Universidad de Jaén, Aula de Literatura Contemporánea.

7. Echeverri, A. (2003). Rompecabezas. En Ardores y furores. Relatos eróticos de escritoras colombianas (pp. 39-47). Bogotá: Planeta.

8. García-Berlanga, L. (1995). Presentación. En: V. Muñoz. Infiernos eróticos (pp. 6-11). Valencia: La Máscara.

9. Gómez, G. (2003). Destape Literario. Caribania Magazine. [Entrada de blog] Disponible en https://bit.ly/2z8MC5a [10.09.18].

10. González, P.; Moreno, B. y Sanmiguel, P. (1997). ¿En qué sentido el psicoanálisis es revolucionario? Bogotá: Aldabón.

11. Hanan, P. (1992). Introducción. En L. Yu. La alfombrilla de los goces y los rezos (pp.11-19). Barcelona: TusQuets. 
12. Jaramillo, A. (2003). Cuerpos jugados. En Ardores y furores. Relatos eróticos de escritoras colombianas (pp. 49-53). Bogotá: Planeta.

13. Jaramillo Seligman, A. (2003). Ella sabe. En Ardores y furores. Relatos eróticos de escritoras colombianas (pp. 55-59). Bogotá: Planeta.

14. Jaramillo Zuluaga, E. (1994). El deseo y el decoro. Puntos de herejía en la novela colombiana. Bogotá: Tercer Mundo editores.

15. Lacan, J. (1989). El Seminario XX. Aun. Buenos Aires: Paidós.

16. Morales, G. (1998). Antología de la literatura erótica. El juego del viento y la luna. Madrid: Espasa.

17. Mosquera, F. (2003). El elegido. En Ardores y furores. Relatos eróticos de escritoras colombianas (pp. 61-71). Bogotá: Planeta.

18. Ospina, D. (2003). Ocultó sus ojos tras los párpados. En Ardores y furores. Relatos eróticos de escritoras colombianas (pp. 73-82). Bogotá: Planeta.

19. Paz, O. (1995). La llama doble. Bogotá: Seix Barral.

20. Peláez, G. (2003). A solas con el científico. En Ardores y furores. Relatos eróticos de escritoras colombianas (pp. 83-89). Bogotá: Planeta.

21. Pérez, L. (2003). Sinfonía erótica. En Ardores y furores. Relatos eróticos de escritoras colombianas (pp. 91-96). Bogotá: Planeta.

22. Reverón Peña, M., y Parra Pérez, M. (2016). No es porno, señoras y señores, es sexoficción: una mirada crítica a la "modernidad" caleña de los años setenta del siglo xx en Colombia en la obra Aventuras de un impotente de Hernán Hoyos. La Palabra 28, pp. 41-58.

23. Samper,A. (2003). "El brazo de reina”. En Ardores y furores. Relatos eróticos de escritoras colombianas (pp. 97-109). Bogotá: Planeta.

24. Serrano, E. (2002). Zaynab. En A. García; Ó. Godoy, et. al. Aaaaaahhh...! Doce relatos eróticos (pp. 121-127). Bogotá: Planeta.

25. Steimberg, A. (1993). Cómo escribir literatura erótica. [Entrada de blog] Disponible en https://bit.ly/2DIGODg [20.05.18]

26. Sontag, S. (1967). La imaginación pornográfica. En Estilos radicales (pp. 44-83). Barcelona: Muchnik Editores.

27. Steiner, G (1973). Sobre la pornografía. Revista Eco 157, pp. 16-28.

28. Torres, D. (2014). Pornoterrorismo. Edición digital. 